\title{
Scientific journalism and the challenge of COVID-19
}

The plethora of scientific publications has reached so far around COVID-19 - which has reached over one hundred thousand articles ${ }^{1}$ in the 10 months of pandemic -this indicates an enormous problem in which humanity urgently needs to solve. This is an amount of communication probably has never seen before, since it is in fact, equivalent to a density of 10,000 publications per month for a single disease, this has never even been observed in major pandemics such as the Acquired Immunodeficiency Syndrome (AIDS), which its communication was much more spread over time. Furthermore, we should not forget that articles from journals which have not yet been indexed, may be accounted for, and included. However, they might bring relevant information. In this case, even high bibliographic data are being underestimated.

Therefore, this is a fundamental answer which scientific journalism is offering to solve this great problem. The question now is: is this a sufficient answer? we only can say that the answer is what scientists and research centers can offerat the moment. In fact, this is already a lot, because at the basis of the articles there is a whole load of previously acquired knowledge that supports this immense scientific production that is revealed by the agencies of communication. However, this is only the beginning of the monster's confrontation, and since then, in oursociety,many other operational activities from responsible organs still need to be unleashed.

Based on the information, it is necessary to make the correct decisions, compatible with the obtained knowledge, and even more, such decisions need to be implemented. This requires concrete and objective conditions, which often becomes extremely difficult, given the material, structural and financial limitations, as well as, poor integration in the coordination of processes, when there is no resistance from the public authority leaders.

Nothing is easy! The population suffers! However, all this must be overcome. Last century, a great English historian Arnold Toynbee, in his work "A Study of History"2 proposed a "Challenge and Response Theory" to explain the survival or the decadence of civilizations. The title of the work comes across as a truism, because in our understanding, an adequate response to the challenge would permit a survival. When we suffer a challenge ourselves, and in these circumstances, we have to face it, and by applying that theory to our present situation, we clearly see that scientific journalism is responding with a maximum capacity of its instruments. We happen to be in a universal tsunami, and we need more and more to place our trust in the resources accumulated by science. In particular, the demand for medicines and vaccines show us the light at the end of the tunnel. Science is great and scientific publication, as its ideal vehicle for communication, is doing its job. And we are in a hurry. We are looking for reliable knowledge, a proper decision making, and the implementation of those decisions.

Everything is urgent, and in this case, haste should not be the enemy of perfection! Let's make it as perfect as possible!

Let us strongly respond to our challenge. Even during the tsunami, the world of scientific communication is fulfilling its task.

Journals in the field of collective health, in moments of epidemics, are among the main agencies in response to the great challenge, and this is not negligible. 
In the case of our Journal, the Brazilian Journal of Mother and Child Health, while fulfilling its tasks on regular publication, as is the case of this issue, is also attentive to the process, by publishing, in parallel a special issue, dedicated exclusively to articles on COVID-19. We believe that everyone's effort on this issue will be worth it!

\section{References}

1. WHO (World Health Organization). Global research on coronavirus disease (COVID-19). Published 2020. [Accessed October 21, 2020]. Available from: https://www.who.int/emergencies/diseases/novel-coronavirus-2019/global-research-on-novel-coronavirus2019-ncov.

2. Toynbee A. Um Estudo de História. Rio de Janeiro: Ed. Record; 1987.

José Eulálio Cabral Filho 1

(iD) https://orcid.org/0000-0001-9121-9910

${ }^{1}$ Editor-in-Chief of the Brazilian Journal of Mother and Child Health. Rua dos Coelhos, 300. Boa Vista. Recife, PE, Brazil. 